\title{
Proportional-Integral Ammonium-based Aeration Control for Activated Sludge Process
}

\author{
M H Husin \\ Department of Electrical and \\ Electronic Engineering \\ Faculty of Engineering, Universiti \\ Malaysia Sarawak, \\ Kota Samarahan, Sarawak, Malaysia \\ hhmaimun@unimas.my \\ M F M Sabri \\ Department of Electrical and \\ Electronic Engineering \\ Faculty of Engineering, Universiti \\ Malaysia Sarawak, \\ Kota Samarahan, Sarawak, Malaysia \\ msmfaizrizwan@unimas.my
}

\author{
M F Rahmat \\ School of Electrical Engineering, \\ Faculty of Engineering, Universiti \\ Teknologi Malaysia, \\ UTM Johor Bahru, Johor, Malaysia \\ fuaad@fke.utm.my \\ S Suhaili \\ Department of Electrical and \\ Electronic Engineering \\ Faculty of Engineering, Universiti \\ Malaysia Sarawak, \\ Kota Samarahan, Sarawak, Malaysia \\ sushamsiah@unimas.my
}

\author{
N A Wahab \\ School of Electrical Engineering, \\ Faculty of Engineering, Universiti \\ Teknologi Malaysia, \\ UTM Johor Bahru, Johor, Malaysia \\ aliza@fke.utm.my
}

\begin{abstract}
Most of the earlier research working on the aeration control of the activated sludge process (ASP) utilized the fixed dissolved oxygen (DO) concentration control strategy. This strategy typically works at elevated level of aeration to avoid nitrification failure and to meet biological oxygen demand (BOD) removal. The problem of elevated aeration is increased cost of aeration, which contribute the most to the total operation cost of wastewater treatment plant (WWTP). Some attempts have been made to solve this problem by utilizing aeration control that has a variation of the DO concentration using ammonium-based aeration control (ABAC) control strategy. The existing controller used is Proportional Integral (PI) controller, which the control gain is fixed. In this study, an adaptive feedback PI-ABAC is proposed using rule-based control technique. The performance assessment of the proposed controller was investigated by simulation using Benchmark Simulation Model No. 1 (BSM1) and the outcomes are compared with the static-gain benchmark-PI strategy. The proposed controller demonstrated better performance and as well as improved efficiency of nitrogen removal by $5.04 \%$, reduced aeration energy by $1.51 \%$, and reduced overall cost index by $0.30 \%$ when compared to static-gain benchmark PI controller.
\end{abstract}

Keywords—activated sludge, aeration control, wastewater treatment

\section{INTRODUCTION}

80 percent of the world's wastewater resulting from human activities is dumped [1], with mostly untreated, back into the rivers or sea which deteriorating the water environment. It is mostly due to inadequate sanitation. In the Sustainable Development Goal (SDG), Goal 6 is to guarantee access to water and sanitation for everyone. Clean water and sanitation are matters to all because the water demand has outpaced population growth and water and sanitation-related diseases stay among the main reasons for death in children under five years old [1].

Clean water is an essential resource for human beings and the environment all over the world. WWTP abet in protecting public health by preserving water resources and protecting the environment for a sustainable future. More stringent effluent standards [2]-[4] were established for WWTP towards a better environment. The biggest challenge faced by the WWTP industry is to come up with solutions that comply with the new standards and is economically viable. Therefore, the WWTP industry is experiencing a surge in the adoption of advanced control in the operation of the WWTP.

WWTP subject to huge disturbances in incoming stream and vagueness concerning the composition of the influent, thus making them hard to control. Furthermore, the operation and process control of WWTP is tough due to complex interaction in the biological phenomena in the ASP itself and the huge range of time constant (vary from minutes to days) of the sludge properties.

The energy expenditure in the ASP can be minimized through proper restrain of the aeration system. It is well known that the aeration section of WWTP is contributed to $50-90 \%$ [5] from the total energy demand of the WWTP. Aeration is required to subtract nitrogen and organic carbon in the ASP. Earlier research working on optimizing the ASP which is associated with the aeration control mostly focuses on the DO concentration, mainly to reduce the cost related to aerators and turbines which are run by electric motors. These have contributed to the usage of energy and maintenance costs. That is why it is a likely target to operate the plant at minimal energy by controlling the DO according to the oxygen demand of the microorganism. However, it is difficult to tell how much the actual oxygen is needed by the microorganism at a certain time. Due to this, many control strategies are designed to control the DO at a pre-set setpoint. The proposed controller varies from a simple PID control [5], [6], and up to a complicated controller such as nonlinear model predictive control [7]-[11], fuzzy and neural network control [12].

Apart from controlling the DO, aeration process can be controlled by using the total aerobic volume and the aeration intensity as suggested by [13]. Though, the study on the aerated volume control is rarely reported. This idea was studied once by [14], which indicated that the ammonium concentration can be regulated to the desired setpoint by controlling the aerated volume. However, there are a growing number of researches can be found in the second method, which is the variation of aeration intensity. The aeration intensity can be varied by changing the level of the DO according to the measurement of the ammonium. This control strategy is also known as ammonium-based aeration control (ABAC). 